\title{
An azaspirane derivative suppresses growth and induces apoptosis of ER-positive and ER-negative breast cancer cells through the modulation of JAK2/STAT3 signaling pathway
}

\author{
NURFARHANAH BTE SYED SULAIMAN ${ }^{1 *}$, CHAKRABHAVI DHANANJAYA MOHAN ${ }^{2 *}$, BASAPPA $^{3 *}$, \\ VIJAY PANDEY ${ }^{1}$, SHOBITH RANGAPPA ${ }^{4}$, HANUMANTHARAYAPPA BHARATHKUMAR ${ }^{3}$, \\ ALAN PREM KUMAR ${ }^{1,5}$, PETER E. LOBIE ${ }^{1,5,6}$ and KANCHUGARAKOPPAL S. RANGAPPA ${ }^{2}$ \\ ${ }^{1}$ Cancer Science Institute of Singapore, National University of Singapore, Singapore 117599; \\ ${ }^{2}$ Department of Studies in Chemistry, University of Mysore, Manasagangotri, Mysore 570006; \\ ${ }^{3}$ Laboratory of Chemical Biology, Department of Chemistry, Bangalore University, Central College Campus, \\ Bangalore 560001, India; ${ }^{4}$ Frontier Research Center for Post-Genome Science and Technology, Hokkaido University, \\ Sapporo 060-0808, Japan; ${ }^{5}$ Department of Pharmacology, Yong Loo Lin School of Medicine, \\ National University of Singapore; ${ }^{6}$ National University Cancer Institute, \\ National University Health System, Singapore
}

Received December 14, 2015; Accepted March 28, 2016

DOI: 10.3892/ijo.2016.3615

\begin{abstract}
Persistent activation of signal transducer and activator of transcription 3 (STAT3) is associated with the progression of a range of tumors. In this report, we present the anticancer activity of 2-(1-(4-(2-cyanophenyl)1-benzyl-1H-indol-3-yl)-5(4-methoxy-phenyl)-1-oxa-3-azaspiro(5,5)undecane (CIMO) against breast cancer cells. We observed that CIMO suppresses the proliferation of both estrogen receptor-negative (ER-) (BT-549, MDA-MB-231) and estrogen receptor-positive $\left(\mathrm{ER}^{+}\right)$(MCF-7, and BT-474) breast cancer (BC) cells with $\mathrm{IC}_{50}$ of $3.05,3.41,4.12$ and $4.19 \mu \mathrm{M}$, respectively, and without significantly affecting the viability of normal cells. CIMO was observed to mediate its anti-proliferative effect in ER- BC cells by inhibiting the phosphorylation of JAK2 and STAT3 proteins. Quantitative $P C R$ analysis demonstrated that CIMO decreases the relative $m R N A$ expression of genes that are involved in cell cycle progression $(C C N D 1)$ and cell survival
\end{abstract}

Correspondence to: Professor Peter E. Lobie, Cancer Science Institute of Singapore, National University of Singapore, Singapore 117599, Republic of Singapore

E-mail: csipel@nus.edu.sg

Professor Kanchugarakoppal S. Rangappa, Department of Studies in Chemistry, Manasagangotri, University of Mysore, Mysore 570006, India

E-mail: rangappaks@yahoo.com

*Contrinbuted equally

Key words: JAK2/STAT3 signaling pathway, breast cancer, azaspirane, anticancer, metastasis
(BCL2, BCL-xL, BAD, CASP 3/7/9, and TP53). In addition, CIMO was observed to arrest BC cells at G0/G1 phase and of the cell cycle. Furthermore, CIMO suppressed BC cell migration and invasion with concordant regulation of genes involved in epithelial to mesechymal transition $(C D H 1, C D H 2, O C L N$ and VIM). Thus, we report the utility of a synthetic azaspirane which targets the JAK-STAT pathway in ER ${ }^{-}$BC.

\section{Introduction}

Breast cancer (BC) is the leading cause of cancer-related death in females worldwide (1). Several studies have shown that the development of $\mathrm{BC}$ is associated with family history, age advancement, mutations in BRCA1, and BRCA2 genes, prolonged exposure to endogenous or exogenous estrogens and exposure to ionizing radiation (2-4). Diagnosis of BC at advanced stages may reduce the efficacy of therapeutic approaches such as surgery and chemotherapy. Approximately $65-70 \%$ of $\mathrm{BCs}$ are $\mathrm{ER}^{+}$and $\mathrm{BC}$ patients with $\mathrm{ER}^{+}$tumors respond positively to adjuvant anti-estrogen therapy, which has produced a significant improvement in survival and a reduction in disease relapse, especially in women with early $\mathrm{BC}$ and those with $\mathrm{ER}^{+}$tumors, who may receive endocrine therapy (ET) alone or in combination with cytotoxic therapy. Approximately $10-20 \%$ of $\mathrm{BCs}^{-}$are $\mathrm{ER}^{-}$and $\mathrm{BC}$ patients with $\mathrm{ER}^{-}$tumor do not respond to hormonal therapy or other targeted therapies (e.g., Herceptin). Therefore, improved prognostic outcomes for $\mathrm{ER}^{-} \mathrm{BC}$ depend on early detection and/or development of new therapeutics with higher efficacy for advanced stage cancer.

Signal transducer and activator of transcription 3 (STAT3) is a latent transcription factor residing in the cytoplasm (5). STAT3 is involved in relaying extracellular signals derived from multiple cytokines, hormones and growth factors to 
the nucleus in order to transcribe the genes involved in cell proliferation, apoptotic resistance, angiogenesis and immune evasion (6-8). Janus kinases and Src kinases are the upstream tyrosine kinases which phosphorylate STAT3 on Tyr-705. In turn, STAT3 undergoes dimerization to translocate into the nucleus to stimulate the transcription of genes involved in the aforementioned functions (9). STAT3 is reported to be constitutively activated in more than 20 types of cancer, including breast cancer, thereby contributing to cancer progression and poor prognosis $(7,10)$. Hence, the critical role of STAT3 in breast cancer makes it an attractive therapeutic target for cancer treatment and potentially $\mathrm{ER}^{-} \mathrm{BC}$.

Azaspirane derivatives are known for their tyrosine kinase inhibitory activity and many are in clinical trials for the treatment of various cancers $(11,12)$. Midostaurin, atiprimod, lestaurtinib and $\mathrm{K} 252 \mathrm{a}$ are some of the major azaspirane based multi-tyrosine kinase inhibitors (13). Midostaurin is an analogue of azaspirane and a derivative of staurosporine which have been tested in phase-II clinical trials for the treatment of acute myeloid leukemia and it potently inhibits protein kinase C, VEGFR2, PDGFR, KIT and FLT3 tyrosine kinases $(14,15)$. Atiprimod proved to be a potent JAK2/ JAK3 inhibitor in preclinical studies (16). Lestaurtinib is an inhibitor of JAK2, FLT3 and TrkA and undergoing phase-III clinical trials in combination chemotherapy to treat acute lymphoblastic leukemia (17-19). K252a is a cell-permeable staurosporine based fungal alkaloid with inhibitory activity against protein kinase $\mathrm{C}$ and trk family kinases (20). K252a has also been reported to block leukemia inhibitory factor-induced STAT3 activation in olfactory receptor neurons (21). We have recently reported the synthesis and anticancer effect of various azaspirane derivatives and demonstrated their mechanism of action in several types of cancers $(7,22,23)$. In our previous study, we reported the development of azaspirane based small molecule, 2-(1-(4-(2-cyanophenyl)1-benzyl-1H-indol-3-yl)-5(4-methoxy-phenyl)-1-oxa-3-azaspiro(5,5)undecane (CIMO) and demonstrated inhibition of the JAK-STAT pathway in hepatocellular carcinoma (7). In continuation of effort in demonstrating the pharmacological properties of various heterocyclic compounds (24-30), in this investigation, we evaluated the effect of CIMO in both $\mathrm{ER}^{+}$and $\mathrm{ER}^{-} \mathrm{BC}$ cell lines.

\section{Materials and methods}

Cell culture and reagents. BC cell lines MCF-7, T47D, BT-474, MDA-MB-231, and BT-549 were obtained from the American Type Culture Collection (ATCC, Rockville, MD, USA) and were cultured as per ATCC propagation instructions. MDA-MB-231 and BT549 cell lines were cultured in Dulbecco's modified Eagle's medium while MCF-7 and BT-474 cell lines were cultured in Roswell Park Memorial Institute. All growth media were supplemented with $10 \%$ heat-inactivated fetal bovine serum (FBS) and $1 \%$ penicillinstreptomycin.

Cell viability assay. The BC cell lines (MCF-7, T47D, BT-474, MDA-MB-231, BT-549) were seeded at $2.5 \times 10^{4} / \mathrm{ml}$ in a $96-w e l l$ plate. After an overnight incubation of cells, the medium was changed to the indicated concentration of CIMO ranging from 0.01 to $10 \mu \mathrm{M}$. Following $72 \mathrm{~h}$ incubation, alamarBlue ${ }^{\circledR}$ dye was added and incubated for $4 \mathrm{~h}$ in the dark, followed by measuring fluorescence activity at an excitation wavelength of $540 \mathrm{~nm}$ and an emission wavelength of $590 \mathrm{~nm}$.

ApoTox-Glo ${ }^{T M}$ Triplex assay. Cells $\left(2 \times 10^{4}\right)$ were seeded with complete medium in each well of a 96 -well plate, $5 \mu \mathrm{M}$ of CIMO and vehicle control (DMSO) was added to the respective well and incubated for $24 \mathrm{~h}$. Thereafter, $20 \mu \mathrm{l}$ of viability/ cytotoxicity reagent containing both GF-AFC substrate and bis-AAF-R110 substrate was added to all the wells, and mixed by orbital shaking $(300-500 \mathrm{rpm}$ for $\sim 30 \mathrm{sec})$ and incubated for $30 \mathrm{~min}$ at $37^{\circ} \mathrm{C}$. After which fluorescence measurement was obtained at the two wavelength sets: $400_{\mathrm{Ex}} / 505_{\mathrm{Em}}$ (viability) $485_{\mathrm{Ex}} / 520_{\mathrm{Em}}$ (cytotoxicity). After measurement, $100 \mu 1$ of Caspase-Glo ${ }^{\circledR}$ 3/7 reagent was added to all the wells, and mixed by orbital shaking (300-500 rpm for $30 \mathrm{sec}$ ) and incubated for $30 \mathrm{~min}$ at room temperature followed by luminescence measurement with an integration time between $0.5-1 \mathrm{sec}$.

3D Matrigel proliferation assay. 3D Matrigel (100\%) (BD BioCoat ${ }^{\mathrm{TM}}$ Matrigel $^{\mathrm{TM}}$ ) was coated on 48-well plates and given time to solidify. A 2\% Matrigel containing 5,000 MDA-MB-231 cells were cast above the $100 \%$ Matrigel layer and given time to solidify. Thereafter, cells were allowed to grow till they formed a 3D morphology before subjecting them to treatment with different concentration of CIMO at 5, 2.5 and $1.25 \mu \mathrm{M}$ in $2 \% \mathrm{FBS}+1 \% \mathrm{P} / \mathrm{S}$ containing high glucose DMEM. The media in the wells were changed every 2 days, with microscopy images obtained every day to observe the drug-induced effects on cells present in a 3D culture.

Flow cytometric analysis. To determine the effect of CIMO on the cell cycle, cells were treated with CIMO at the indicated concentrations $\leq 5 \mu \mathrm{M}$. Thereafter, cells were washed, fixed with $70 \%$ ethanol, and incubated for $30 \mathrm{~min}$ at $37^{\circ} \mathrm{C}$ with $0.1 \%$ RNase A in PBS. Cells were then washed again, resuspended, and stained in PBS containing $25 \mu \mathrm{g} / \mathrm{ml}$ propidium iodide for $30 \mathrm{~min}$ at room temperature. Cell distribution across the cell cycle was examined with a Beckman Coulter flow cytometer.

Western blotting. Western blot analysis was performed as previously described (31,32). Briefly, CIMO treated MDA-MB-231 whole-cell extracts were lysed in lysis buffer (20 mM Tris, pH 7.4), $250 \mathrm{mM} \mathrm{NaCl,} 2$ mM EDTA (pH 8.0), $0.1 \%$ Triton $\mathrm{X}-100,0.01 \mathrm{mg} / \mathrm{ml}$ aprotinin, $0.005 \mathrm{mg} / \mathrm{ml}$ leupeptin, $0.4 \mathrm{mM}$ PMSF, and $4 \mathrm{mM} \mathrm{NaVO}_{4}$ ). Lysates were then spun at $14,000 \mathrm{rpm}$ for $10 \mathrm{~min}$ to remove insoluble material and protein concentration was quantified. Thereafter, proteins were resolved on SDS gel. After electrophoresis, the proteins were electrotransferred to a nitrocellulose membrane, blocked with $5 \%$ non-fat milk, and probed with various antibodies overnight at $4^{\circ} \mathrm{C}$. The blot was washed, exposed to HRP-conjugated secondary antibodies for $1 \mathrm{~h}$, and finally examined by chemiluminescence (ECL; GE Healthcare).

Real-time PCR. Quantitative analysis of mRNA expression by real-time PCR was performed using ABI 7700 real-time PCR system (Applied Biosystems) as previously described 
A

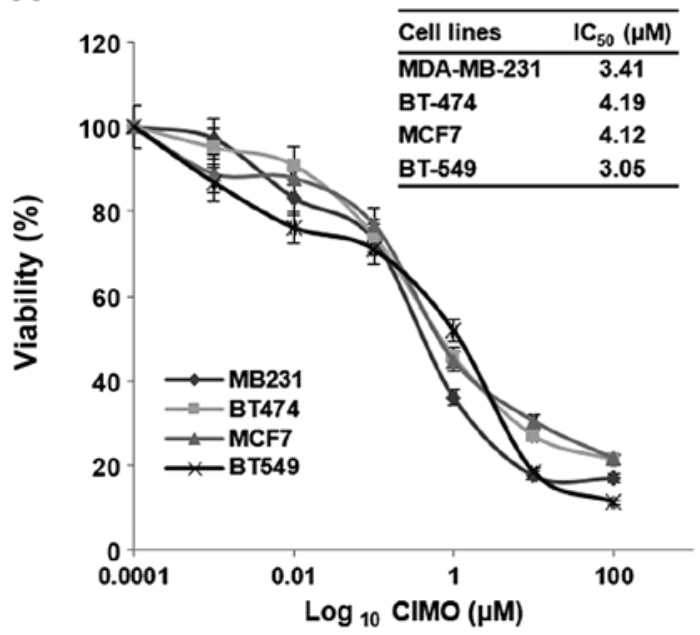

C

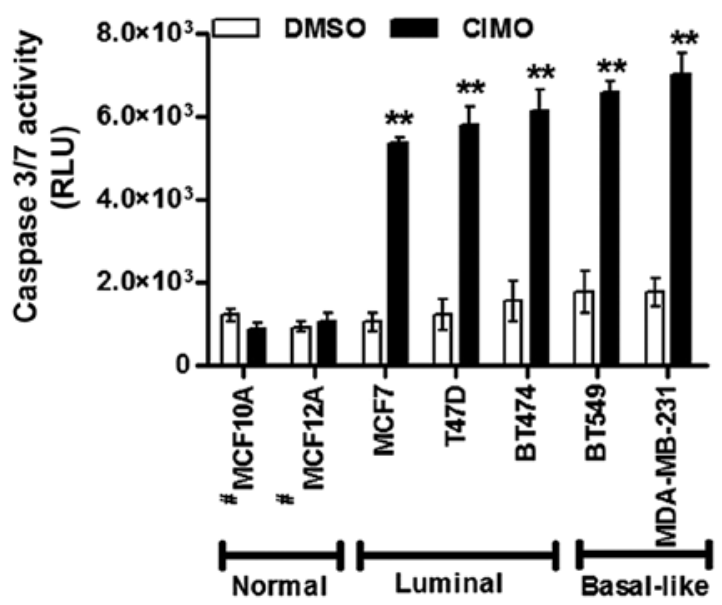

B

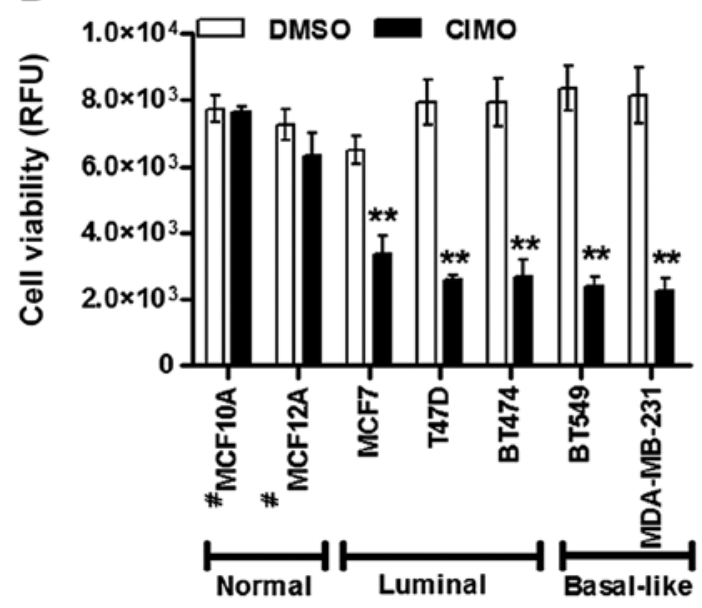

D

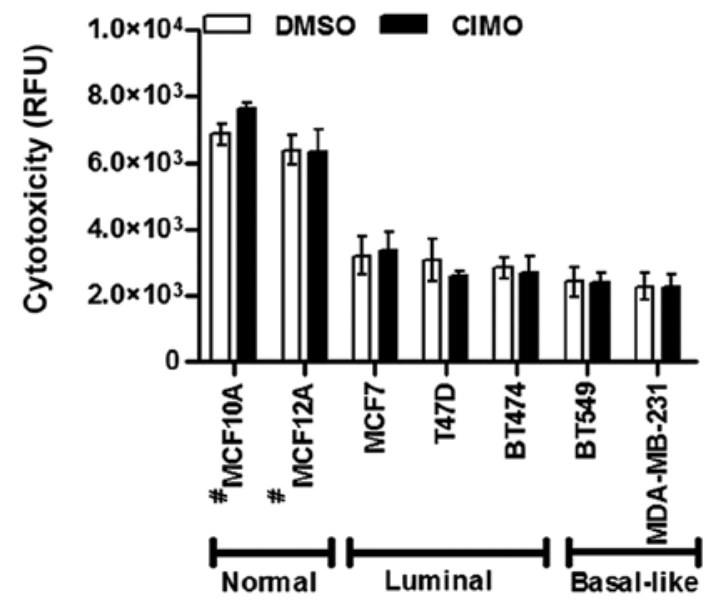

Figure 1. (A) Cell viability. Determination of $\mathrm{IC}_{50}$ values for CIMO on mammary carcinoma cell lines MCF-7, BT474, MB231 and BT549 using alamarBlue. Dose-response curve obtained with CIMO treatment for $72 \mathrm{~h}$. ApoTox-Glo Triplex assay was performed on normal immortalized cell lines MCF10A, MCF12A, luminal cancer cells MCF-7, T47D, BT474 and basal like cancer cell lines B7-549, MDA-MB-231 treated with $5 \mu$ M CIMO for 24 h to determine (B) cellular viability, (C) apoptosis and (D) cytotoxicity.

(33). Briefly, total cDNA (5 ng) from each stable cell line was added to a $20 \mu \mathrm{l}$ reaction containing SYBR GreenER qPCR SuperMix and forward and reverse primer mix. All reactions were performed in triplicate in a 384-well plate using a two-step amplification program with 24 initial denaturation at $95^{\circ} \mathrm{C}$ for $10 \mathrm{~min}$, followed by 40 cycles of $95^{\circ} \mathrm{C}$ for $20 \mathrm{sec}$ and $6^{\circ} \mathrm{C}$ for $30 \mathrm{sec}$. Relative mRNA expression between cDNA samples was calculated using comparative $\mathrm{Ct}$ method and normalized against a panel of housekeeping genes including $\beta$-actin, HPRT, and GAPDH. Relative expression was computed as: Fold expression $=2^{-\Delta \mathrm{Ct}}$ where $\Delta \mathrm{Ct}=\mathrm{Ct}$ difference of sample relative to control $\left(\Delta \mathrm{Ct}^{\text {sample-control }}\right)$. Positive and negative relative expression indicates increase and decrease in mRNA levels, respectively. A P-value $<0.05$ was considered as statistically significant.

Wound healing assay. The migration of cells was investigated using a wound healing assay. MDA-MB-231 cells were seeded in a $6-\mathrm{cm}$ culture dish with complete medium and allowed to grow until $\sim 80 \%$ confluent. A wound was created using a pipette tip and rinsed with PBS to remove detached cells before the treatment with varying concentration of CIMO. The microscopic observation of the cells was recorded as described previously (34).

Invasion assay. The invasion assay was performed with slight modifications in a method described previously (35). A BD Biocoat Matrigel ${ }^{\mathrm{TM}}$ invasion chamber with $8-\mu \mathrm{m}$ pores in the light-tight polyethylene terephthalate membrane and was coated with a reconstituted basement membrane gel (BD Biosciences). MDA-MB-231 cells $\left(1 \times 10^{4}\right)$ were suspended in serum-free DMEM and seeded into the Matrigel Transwell chambers. The cells were incubated with different concentrations of CIMO $(1.25,2.5$ and $5 \mu \mathrm{M})$. After 24-h incubation, the wells were gently removed with cotton swabs. The Transwell insert was fixed in $4 \%$ PFA for $15 \mathrm{~min}$ at $4^{\circ} \mathrm{C}$. Thereafter, the insert was washed twice in PBS and stained with Hoechst. The invading cells were then counted in randomly selected areas under microscopic observation.

Data analysis. All data analysis was done using the GraphPad Prism (V.60f) software. The data given in this study are 
A

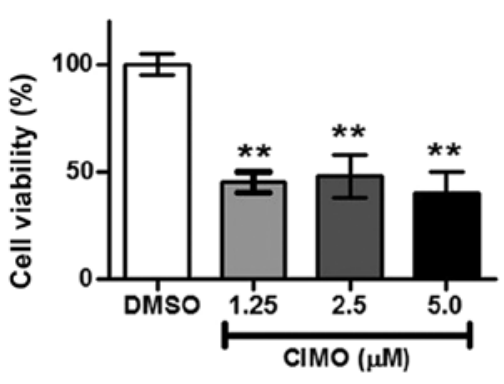

B

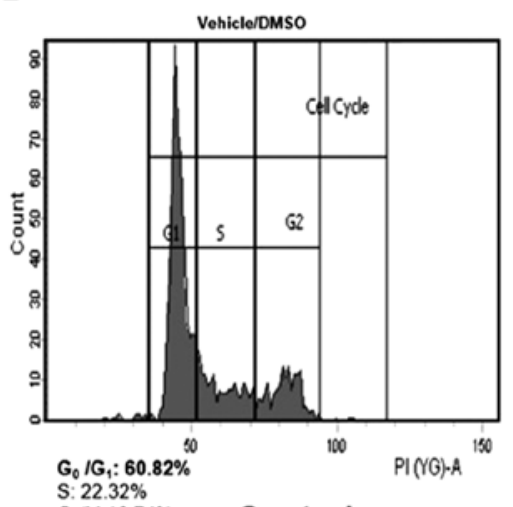

Control

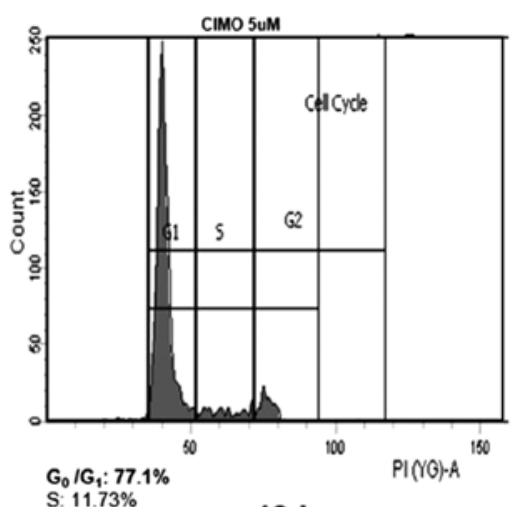

$48 \mathrm{~h}$ S: $11.73 \%$

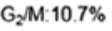

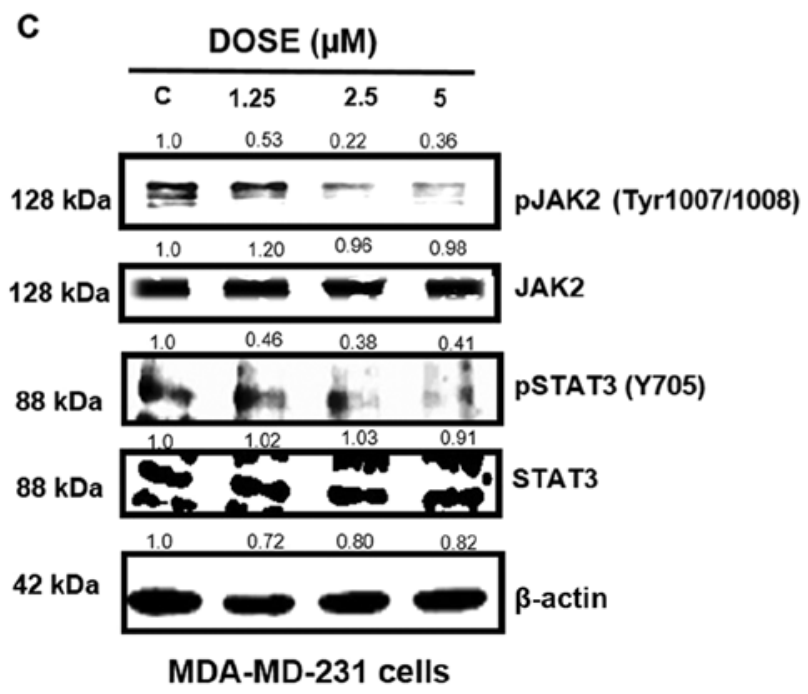

D

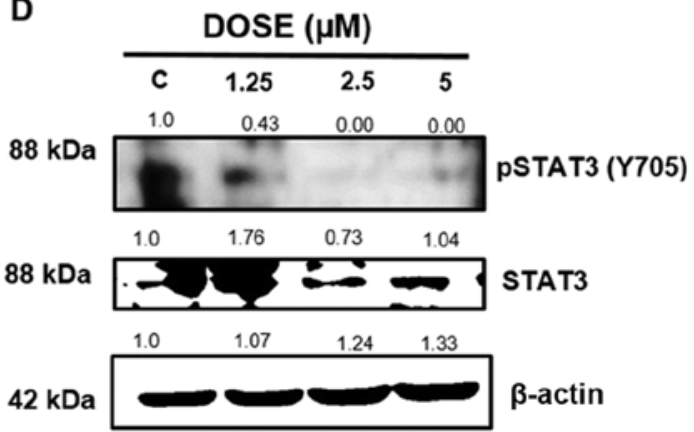

MCF-7 cells

Figure 2. (A) 3D Matrigel. MDA-MB-231 cells $\left(2.5 \times 10^{4}\right)$ were cultured on BD BioCoat Matrigel with or without CIMO, cell viability was measured on day 10 using fluorescence intensity reading obtained at $580 \mathrm{~nm}$ using alamarBlue assay, ${ }^{*} \mathrm{P}<0.05$, unpaired t-test with Welch's correction. (B) Cell cycle analysis for MDA-MB-231 cells treated with $5 \mu \mathrm{M}$ CIMO and vehicle control DMSO for $48 \mathrm{~h}$ after which cells were fixed and stained with PI for analysis of DNA content by flow cytometry. (C) Western blot. CIMO suppresses phospho-JAK2 and phospho-STAT3 in ER cells. MDA-MB-231 cells ( $1 \mathrm{x} 10^{6}$ cells $\left./ \mathrm{ml}\right)$ were treated with the indicated concentrations of CIMO for $24 \mathrm{~h}$, after which whole-cell extracts were prepared and resolved on SDS-PAGE gel, electrotransferred onto PVDF membrane, and probed for phospho-JAK2 (Tyr-1007/1008) and phospho-STAT3 (Tyr-705). The respective blot was stripped and reprobed with JAK2 and STAT3 antibody to verify equal protein input. (D) Western blot. CIMO suppresses phospho-STAT3 in ER ${ }^{+}$cells. MCF-7 (1x10 cells/ml) were treated with the indicated concentrations of CIMO for $24 \mathrm{~h}$, after which whole-cell extracts were prepared and resolved on SDS-PAGE gel, electrotransferred onto PVDF membrane, and probed for phospho-STAT3 (Tyr-705). The respective blot was stripped and reprobed with STAT3 antibody to verify equal protein input. $\beta$-actin was used as input control.

the mean $\pm \mathrm{SD}$ with $\mathrm{n}=3$. An unpaired t-test was used with Welch's correction for statistical analysis between treatment and control, with ${ }^{*} \mathrm{P}<0.05$ and ${ }^{* *} \mathrm{P}<0.01$ in the figures.

\section{Results}

CIMO suppresses proliferation of $E R^{+}$and $E R^{-} B C$ cells. Initially, we evaluated the effect of CIMO on a panel of five BC cell lines (ER ${ }^{+}$: MCF-7, T47D, and BT-474 and ER: MDA-MB-231 and BT-549) using an alamarBlue cell viability assay. The dose-response curve indicated that CIMO was able to produce a substantial decrease in cell viability in all cell lines with BT-549 exhibiting relatively the lowest $\mathrm{IC}_{50}$ value of 3.05 $\mu \mathrm{M}$ followed by MDA-MB-231, MCF-7 and BT-474 with the $\mathrm{IC}_{50}$ values $3.41,4.12$ and $4.19 \mu \mathrm{M}$, respectively (Fig. 1A). The ApoTox-Glo ${ }^{\mathrm{TM}}$ triplex assay results indicated a decreased cellular viability with higher apoptotic activity in both MDA-MB-231 cells than BT-549 cells (Fig. 1B-D). Nevertheless, across all BC cell lines, significantly higher apoptotic levels were detected with a corresponding decrease in cellular viability. CIMO exhibited no substantial cytotoxicity against normal immortalized mammary epithelial cells and/or against BC cell lines.

CIMO decreases proliferation of MDA-MB-231 cells in $3 D$ culture. Tumor cells are more resistant to anticancer agents in three-dimensional multicellular spheroidal conformation compared to monolayer culture (36). Therefore, we analyzed the effect of CIMO on 3D culture of MDA-MB-231 cells. $\mathrm{BC}$ cells were cultured in Matrigel, treated with CIMO at indicated doses and cellular viability was measured with alamarBlue on day 10. Treatment with CIMO decreased the 
A

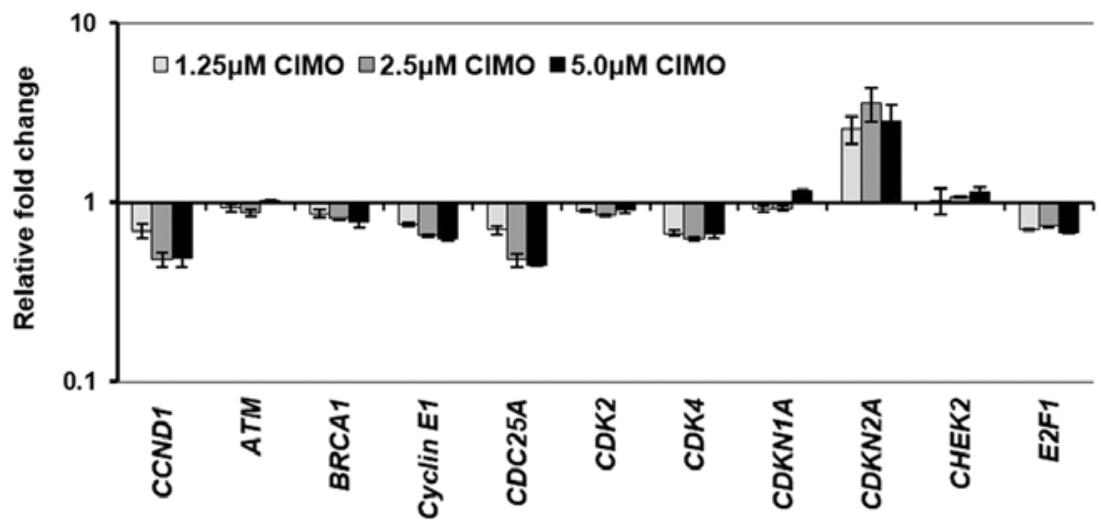

C

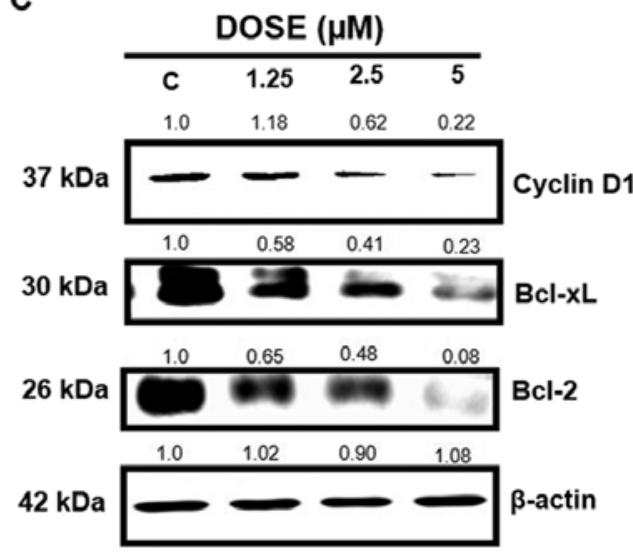

B

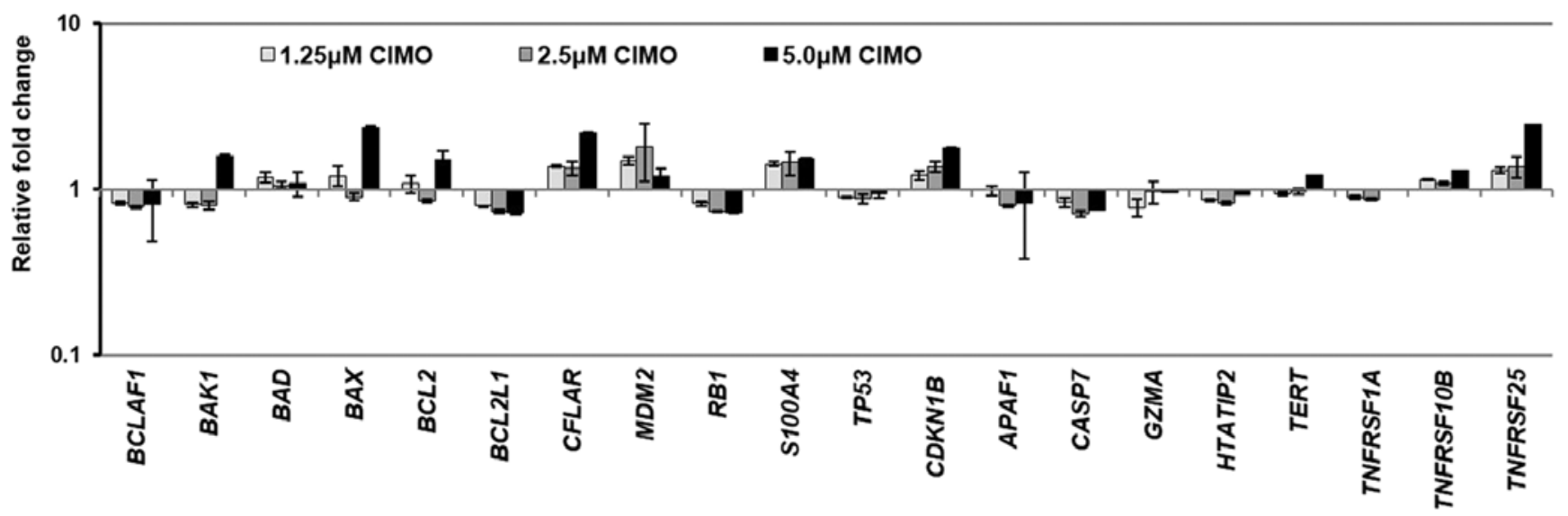

Figure 3. (A) $m R N A$ levels of molecular markers involved in cell proliferation. (B) $m R N A$ levels of molecular markers involved in apoptosis and cell senescence. (A and B) Quantitative (q) PCR analyses of MDA-MB-231 cells after exposure to CIMO for $m R N A$ levels of key genes functionally involved in cell proliferation, survival, senescence and apoptosis. Change in gene expression is expressed as relative fold difference compared to vehicle (DMSO) exposed cells. (C) Western blot. MDA-MB-231 cells $\left(1 \times 10^{6}\right.$ cells $\left./ \mathrm{ml}\right)$ were treated with the indicated concentrations of CIMO for $24 \mathrm{~h}$, after which whole-cell extract were prepared and resolved on SDS-PAGE gel, electrotransferred onto PVDF membrane, and probed for cell cycle protein CCND1, anti-apoptotic proteins BCL2 and BCL-xL.

cell viability by $>50 \%$ compared to vehicle control in $3 \mathrm{D}$ culture (Fig. 2A).

CIMO arrests MDA-MB-231 cells at G0/G1 phase. In order to evaluate the effect of CIMO on the distribution of the cell cycle in MDA-MB-231 cells, we performed flow cytometric analysis. MDA-MB-231 cells were treated with CIMO at different time intervals up to $48 \mathrm{~h}$ and stained with propidium iodide to analyze the cell cycle distribution. We observed that CIMO increased the accumulation of cells in G0/G1 phase of the cell cycle (Fig. 2B). The treatment of BC cells with $5 \mu \mathrm{M}$ of CIMO for $48 \mathrm{~h}$ resulted in an increased $\mathrm{G} 0 / \mathrm{G} 1$ population of $77.1 \%$ compared to $60.82 \%$ in vehicle control.

CIMO suppresses the basal activation of STAT3 in $E R^{+}$and $E R^{-}$cells. Azaspiranes have been reported to possess inhibitory activity against the JAK-STAT pathway. Therefore, we further evaluated the inhibitory potential of CIMO towards the activity of JAK2 and STAT3 in ER- (MDA-MB-231) and STAT3 in $\mathrm{ER}^{+}$cells by western blotting via antibodies recognizing phospho-JAK2 (Tyr-1007/1008) and phospho-STAT3 (Tyr-705). We observed that, CIMO significantly inhibited the phosphorylation of JAK 2 and STAT 3 in a dose-dependent manner, with a maximum inhibition identified at $5 \mu \mathrm{M}$ and $6 \mathrm{~h}$. At the same time, the expression of total JAK2 and STAT3 proteins remained unaltered (Fig. 2C and D).

CIMO downregulates the expression of STAT3 targeted genes in $M D A-M B-231$ cells. Activated STAT3 has been reported to modulate the expression of antiapoptotic proteins $(37,38)$. Therefore, we evaluated whether CIMO modulates the expression of various STAT3-regulated genes. Real-time PCR analysis demonstrated that exposure of MDA-MB-231 cells to CIMO decreased $m R N A$ levels of CCND1, CCNE1, CDK2 and $C D K 4$ required for cell cycle progression (39). In addition, the $m R N A$ levels of $C D K N 2 A$ an inhibitor of $C D K 4$ was increased in MDA-MB-231 cells treated with CIMO relative to vehicle exposed cells (40). CIMO treated MDA-MB-231 cells exhibited decreased $m R N A$ levels of the pro-survival gene, $B C L-x L$. Concordantly, the $m R N A$ levels of genes encoding proapoptotic $M D M 2, S 100 A 4, B A X$ and $C D K N 1 B$ were increased after CIMO exposure in MDA-MB-231 cells (Fig. 3A and B). Furthermore, western blot analysis demonstrated that protein levels of CCND1 and BCL2 and BCL-xL were decreased in MDA-MB-231 cells after treatment with CIMO in a dosedependent manner (Fig. 3C). 


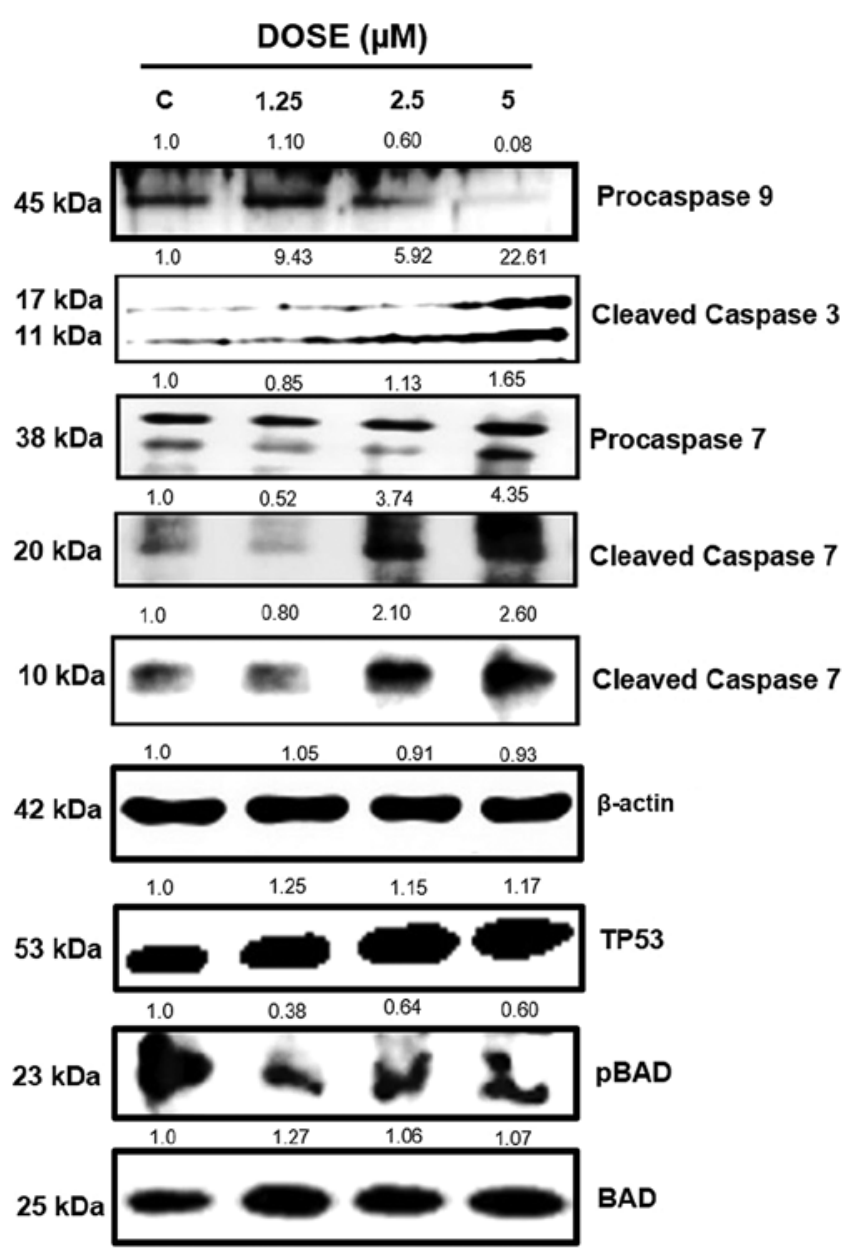

Figure 4. Western blot. CIMO promotes apoptosis via the mitochondrial pathway in MDA-MB-231 cells. MDA-MB-231 cells $\left(1 \times 10^{6}\right.$ cells $\left./ \mathrm{ml}\right)$ were treated with the indicated concentrations of CIMO for $24 \mathrm{~h}$, after which wholecell extract was prepared and resolved on SDS-PAGE gel, electrotransferred onto PVDF membrane, and probed for caspase 3, 7 and 9 along with CCND1, TP53, phospho-BAD and BAD. $\beta$-actin was used as input control.

CIMO promotes apoptosis via the mitochondrial pathway in MDA-MB-231 cells. Cleavage of pro-caspase 9 serves as a marker of cells undergoing apoptosis via the mitochondrial pathway with subsequent activation of the executioner caspase 3 and 7 (41). We therefore investigated whether CIMO promoted apoptosis through the intrinsic pathway in MDA-MB-231 cells. We observed that, CIMO treatment produced a decrease in the level of pro-caspase 9 and increased levels of cleaved caspase 3 and 7 as direct evidence of mitochondrial mediated apoptosis (Fig. 4). Dephosphorylation of BAD protein at Ser-136 results in dimerization with BCL2 and BCL-xL to induce the release of cytochrome $c$ to promote apoptosis via the intrinsic pathway (42). Treatment with CIMO decreased BAD phosphorylation in a dose-dependent manner. In addition, we also observed an increased expression of TP53 (Fig. 4).

CIMO suppresses cell invasion and migration in MDA-MB231 cells. STAT3 regulated gene products are also reported to be associated with migration and invasion of cancer cells $(6,7)$. To evaluate whether CIMO repressed the motility of cancer cells, we performed a wound healing assay. CIMO significantly inhibited cell migration at $5 \mu \mathrm{M}$ (Fig. 5A). Further investigation using Transwell invasion chamber demonstrated that CIMO inhibited the invasion of BC cells (Fig. 5B). Loss of CDH1 and OCLN promotes invasiveness, and increased expression of CDH2 and VIM is correlated with metastasis and poor prognosis in human cancers (43-46). Given the anti-invasive property of CIMO, we further analyzed the expression of epithelial-mesenchymal transition proteins including $\mathrm{CDH}$, $C D H 2, O C L N$ and VIM. Fig. 5C demonstrates the upregulation of $C D H 1$ and $O C L N$ and downregulation of $C D H 2$ and $V I M$ in a dose-dependent manner.

We next evaluated the effect of siRNA-mediated deletion of STAT3 transcripts on cell invasion. Transient transfection of STAT3-directed siRNA in MDA-MB-231 cells showed decreased levels of phospho-STAT3 and STAT3 protein compared with their respective controls which was confirmed using western blot analysis. We also observed the decreased phosphorylation of STAT3 on treatment with CIMO without altering the levels of total STAT3 (Fig. 6). Cells transfected and/or exposure to CIMO exhibited reduced invasion and migratory properties when compared to DMSO treated cells indicating that deletion/inhibition of STAT3 plays a critical role in motility of cancer cells.

\section{Discussion}

STAT3, upon phosphorylation, dimerizes and translocate to the nucleus where it relays its oncogenic signals via regulating genes involved in cell growth, survival, angiogenesis, and cell migration $(22,39,40,42)$. Hence, it is no surprise that a mutation in this gene alone can support oncogenic activity and give rise to uncontrolled cell proliferation (31). JAK2, a non-receptor tyrosine kinase promoting STAT3 activation was observed to be constitutively activated in $>50-60 \%$ of primary breast tumors and tumor-derived cell lines with drug resistance (32). Hence, inhibition of JAK2/STAT3 signaling is an attractive approach in disrupting aggressive subtypes of breast cancer including $\mathrm{ER}^{-} \mathrm{BC}$. The aim of this study was to further investigate the effects of the oxazine-based compound CIMO, that has been recently reported to disrupt the JAK-STAT pathway in hepatocellular carcinoma. In $\mathrm{ER}^{+}$and $\mathrm{ER}^{-} \mathrm{BC}, \mathrm{CIMO}$ inhibits the kinase activation of JAK2 and hence subsequently reduces the JAK2 mediated activation of STAT3 specifically at Y705. As previous studies have demonstrated that CIMO has no effect on S727 phosphorylation of STAT3 in hepatocellular carcinoma cells, the phosphorylation activity at S727 of STAT3 was not investigated.

Constitutive activation of STAT3 by receptor tyrosine kinases EGFR, HER2, fibroblast growth factor receptor (FGFR), IGFR, HGFR and platelet-derived growth factor receptor (PDGFR), growth hormone, prolactin, receptorassociated kinases (JAK) and non-receptor kinases (Src and ABL) through phosphorylation has been documented in $\mathrm{BC}$ cells (47-49). This constitutive STAT3 activation leads to increased expression of proteins such as MMP-2, MMP1, MEK5, c-Fos and VEGF and promote invasion (25). As such, the ability of CIMO to suppress invasion was evident and due to its ability to disrupt the JAK2/STAT3 pathway. Constitutive STAT3 activation is able to promote EMT via STAT3 promoted SNAIL1 expression including increased 
A

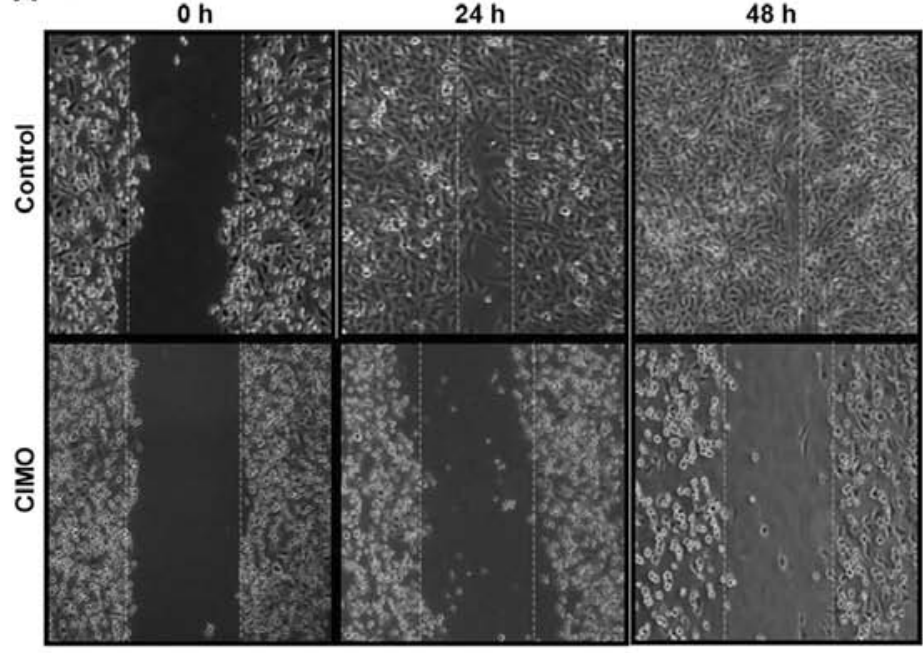

C

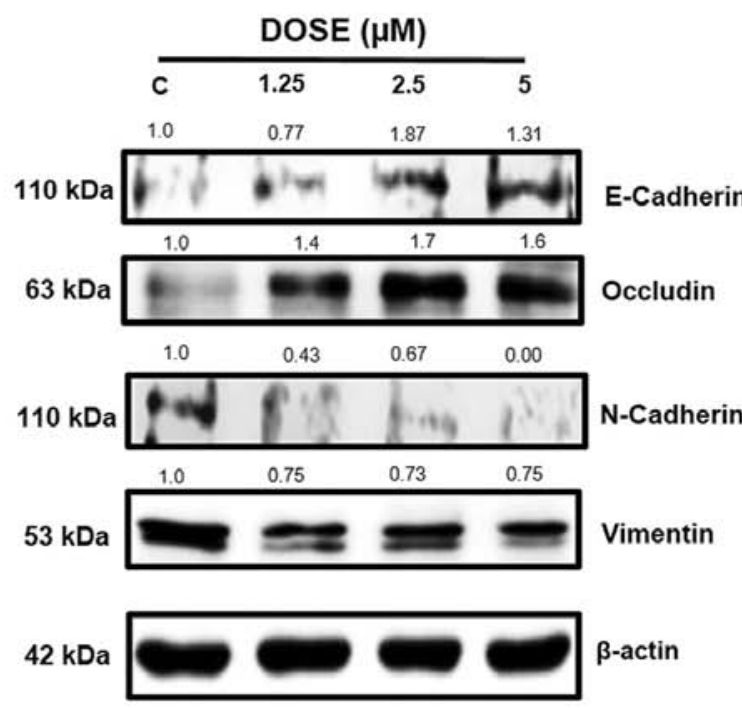

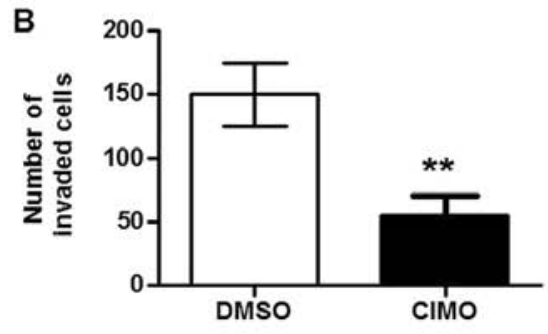

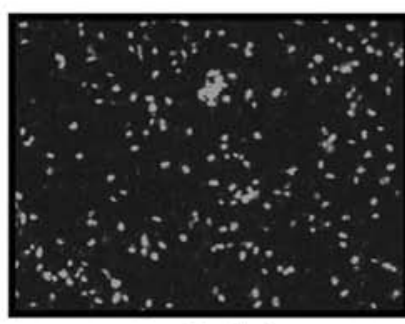

Control

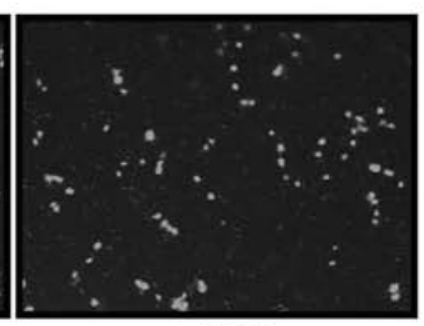

CIMO

Figure 5. (A) Wound healing assay. CIMO inhibits cell migration. MDA-MB-231 cells $\left(1 \times 10^{6}\right)$ were plated on a 6-cm culture dish with complete medium. After 24-h incubation and ensuring cells were $100 \%$ confluent, media was removed and a scratch were performed on the plate using a P200 pipette tip. The cells were than rinsed twice with PBS before CIMO treatment. Images to monitor the migration of cells were than taken at different time-points of 0,24 and $48 \mathrm{~h}$ using microscopy under x 5 and x10 magnifications. (B) Transwell assay. CIMO inhibits cell invasion. MDA-MB-231 cells suspended in serum-free DMEM were seeded in the top chamber of a 5\% Matrigel (BD BioCoat Matrigel) gel layer in a 24-well Transwell insert (Greiner bio-one ThinCert 24-well culture insert; $8.0 \mu \mathrm{M})$. After which, CIMO or vehicle DMSO in serum-free media were added followed by the chemoattractant, DMEM containing $10 \%$ FBS was added to the 24-well plates. Following 24-h incubation, Transwell inserts were fixed in 4\% PFA for 15 min at $4{ }^{\circ} \mathrm{C}$ and washed with PBS before staining with Hoechst $(1 \%$ Triton X-100 $+4 \mu \mathrm{g} / \mathrm{ml}$ Hoechst dye 33258). (C) Western blot. Whole cell lysate obtained after $24 \mathrm{~h}$ CIMO treatment and vehicle control DMSO were run on SDS-page gel and transferred to PVDF membrane which were probed for CDH1, CDH2, OCLN and VIM. $\beta$-actin was used as input control.
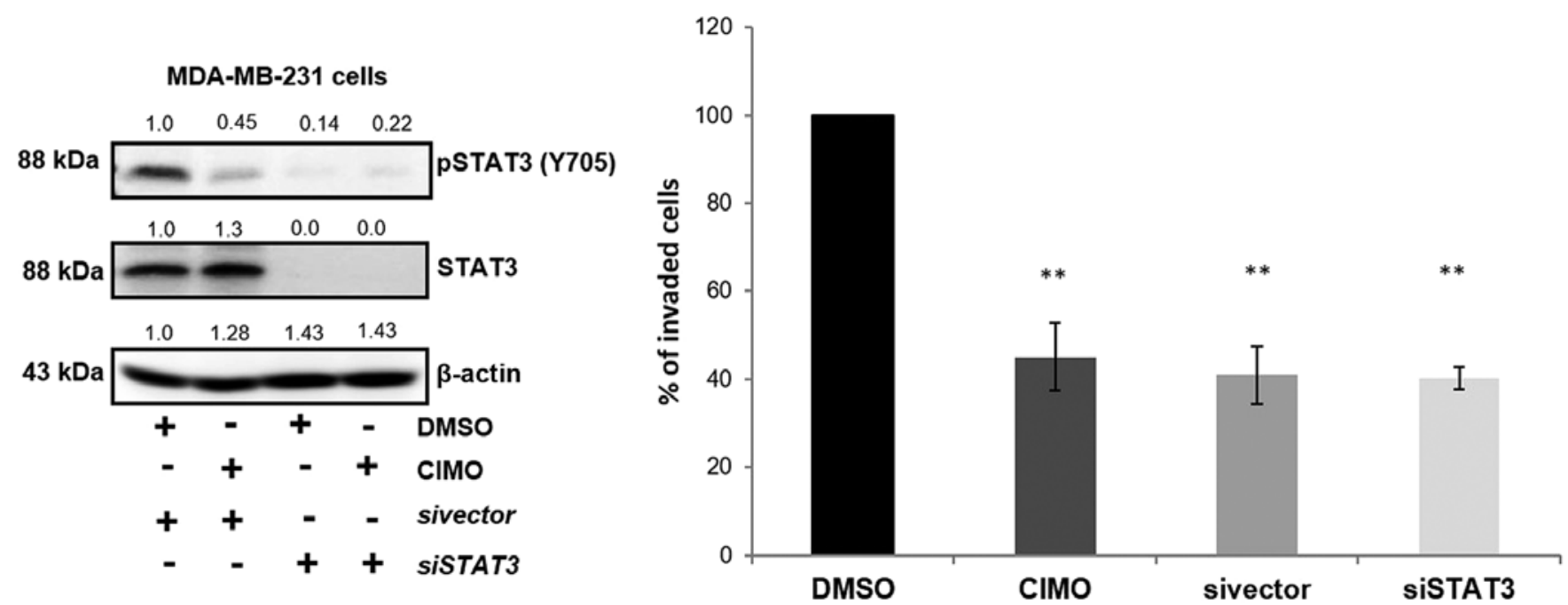

Figure 6. Comparative study of cell invasion between STAT3-siRNA-transfected and CIMO-treated MDA-MB-231 cells. Correspondingly, western blot analysis was used to assess the levels of phospho-STAT3 and STAT3 in MDA-MB-231 cells with siRNA-mediated depletion of STAT3 expression and upon exposure to CIMO. Whole-cell extract was prepared and resolved on SDS-polyacrylamide gel, electrotransferred onto nitrocellulose membrane, and probed for phospho-STAT3, and the same blot was stripped and reprobed with STAT3 antibody and $\beta$-actin was used as input control. 
expression of mesenchymal proteins VIM and CDH2 (26,27). In particular, MDA-MB-231 cells exhibiting higher STAT3 activity have shown to have a higher VIM expression (50). Hence, CIMO was able to decrease the expression of EMT proteins via the inactivation of STAT3. This demonstrates the effect of CIMO on suppressing STAT3 mediated migration and invasion in ER BC cells.

Inhibition of JAK2 and STAT3 activity by CIMO directly correlated with decreased expression of STAT3-regulated proteins BCL2, BCL-xL and CCND1. In association with other proteins, BCL2 and BCL-xL protein maintain the integrity of outer membrane of mitochondria in the cells. Herein, we demonstrated that CIMO exposure to ER ${ }^{-}$BC cells increased cleavage of caspase 9 by subsequently increased cleaved caspase 3 and 7, which signify the induction of late-phase intrinsic apoptosis. Concordantly, CIMO exposure to $\mathrm{ER}^{-} \mathrm{BC}$ cells also increased expression of $\mathrm{BAD}$ protein that indicated the induction of mitochondrial outer membrane permeabilization (MOMP) that leads to intrinsic apoptosis, as interaction between dephosphorylated-BAD and BCL2/BCL-xL protein consequent to permeabilization of the mitochondrial outer membrane (51). Moreover, CIMO exposure to $\mathrm{BC}$ cells also decreases expression of CCND1 and stimulates a proliferative arrest in G0/G1 phase that indicated the disruption of the cell cycle progression. Together, CIMO exposure to ER- $\mathrm{BC}$ cells inhibits cell cycle progression and survival.

In conclusion, the design of therapeutic agents against ER ${ }^{-} \mathrm{BC}$ remains as a prime challenge in clinical management of BC. Herein, we report that the azaspirane based small molecule, CIMO as an inhibitor of the JAK2-STAT3

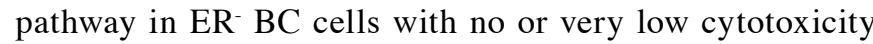
towards normal cells. CIMO promotes apoptosis through the repression of STAT3 activity on target genes. In addition, CIMO suppressed cellular migration and invasion mediated via STAT3 regulated EMT related proteins. Therefore, CIMO emerges as a potential inhibitor targeting the ER $\mathrm{BC}^{-}$ cells whose growth is dependent on the constitutive activation of the JAK2/STAT3 signaling pathway (52).

\section{Acknowledgements}

This study was supported by University Grants Commission (41-257-2012-SR), Vision Group Science and Technology, Department of Science and Technology (no. SR/FT/ LS-142/2012) to Basappa. K.S.R. would like to thank Department of Science and Technology Indo-Korea (INT/ Indo-Korea/122/2011-12) and Institution of Excellence, University of Mysore for financial support. This study was also supported by grants from the National Medical Research Council of Singapore (R-713-000-177-511), and by the NCIS Yong Siew Yoon Research Grant through donations from the Yong Loo Lin Trust to A.P.K. P.E.L. and A.P.K. were supported by grants from the NMRC Clinician Scientist IRG (R-713000-163-511) and the National Research Foundation Singapore and the Singapore Ministry of Education under its Research Centers of Excellence initiative to Cancer Science Institute of Singapore, National University of Singapore. C.D.M. would like to thank the University of Mysore for Department of Science and Technology-Promotion of University Research and Scientific Excellence (DST-PURSE) Research Associate fellowship.

\section{References}

1. Jemal A, Bray F, Center MM, Ferlay J, Ward E and Forman D: Global cancer statistics. CA Cancer J Clin 61: 69-90, 2011.

2. Narod SA, Dubé M-P, Klijn J, Lubinski J, Lynch HT, Ghadirian P, Provencher D, Heimdal K, Moller P, Robson M, et al: Oral contraceptives and the risk of breast cancer in BRCA1 and BRCA2 mutation carriers. J Natl Cancer Inst 94: 1773-1779, 2002.

3. Donovan M, Tiwary CM, Axelrod D, Sasco AJ, Jones L, Hajek R, Sauber E, Kuo J and Davis DL: Personal care products that contain estrogens or xenoestrogens may increase breast cancer risk. Med Hypotheses 68: 756-766, 2007.

4. Ronckers CM, Erdmann CA and Land CE: Radiation and breast cancer: A review of current evidence. Breast Cancer Res 7: 21-32, 2005.

5. Srinivasa V, Li F, Siveen KS, et al: Synthesis and biological evaluation of tetrahydropyridinepyrazoles ('PFPs') as inhibitors of STAT3 phosphorylation. MedChemComm 5: 32-40, 2014.

6. Huang S: Regulation of metastases by signal transducer and activator of transcription 3 signaling pathway: Clinical implications. Clin Cancer Res 13: 1362-1366, 2007.

7. Mohan CD, Bharathkumar H, Bulusu KC, Pandey V, Rangappa S, Fuchs JE, Shanmugam MK, Dai X, Li F, Deivasigamani A, et al: Development of a novel azaspirane that targets the Janus kinasesignal transducer and activator of transcription (STAT) pathway in hepatocellular carcinoma in vitro and in vivo. J Biol Chem 289: 34296-34307, 2014

8. Siveen KS, Sikka S, Surana R, Dai X, Zhang J, Kumar AP, Tan BK, Sethi G and Bishayee A: Targeting the STAT3 signaling pathway in cancer: Role of synthetic and natural inhibitors. Biochim Biophys Acta 1845: 136-154, 2014.

9. Lee JH, Kim C, Sethi G and Ahn KS: Brassinin inhibits STAT3 signaling pathway through modulation of PIAS-3 and SOCS-3 expression and sensitizes human lung cancer xenograft in nude mice to paclitaxel. Oncotarget 6: 6386-6405, 2015.

10. Bromberg J: Stat proteins and oncogenesis. J Clin Invest 109: 1139-1142, 2002

11. Strati P, Kantarjian H, Ravandi F, Nazha A, Borthakur G, Daver N, Kadia T, Estrov Z, Garcia-Manero G, Konopleva M, et al: Phase I/II trial of the combination of midostaurin (PKC412) and 5-azacytidine for patients with acute myeloid leukemia and myelodysplastic syndrome. Am J Hematol 90: 276-281, 2015.

12. M.D. Anderson Cancer Center: Study of atiprimod treatment for patients with advanced cancer. https://clinicaltrials.gov/ct2/show/ NCT00430014. Verified February 2012.

13. Aubert L, Guilbert M, Corbet C, Génot E, Adriaenssens E, Chassat T, Bertucci F, Daubon T, Magné N, Le Bourhis X, et al: NGF-induced TrkA/CD44 association is involved in tumor aggressiveness and resistance to lestaurtinib. Oncotarget 6: 9807-9819, 2015.

14. Millward MJ, House C, Bowtell D, Webster L, Olver IN, Gore M, Copeman M, Lynch K, Yap A, Wang Y, et al: The multikinase inhibitor midostaurin (PKC412A) lacks activity in metastatic melanoma: A phase IIA clinical and biologic study. Br J Cancer 95: 829-834, 2006.

15. Stone RM, DeAngelo DJ, Klimek V, Galinsky I, Estey E, Nimer SD, Grandin W, Lebwohl D, Wang Y, Cohen P, et al: Patients with acute myeloid leukemia and an activating mutation in FLT3 respond to a small-molecule FLT3 tyrosine kinase inhibitor, PKC412. Blood 105: 54-60, 2005.

16. Quintás-Cardama A, Manshouri T, Estrov Z, Harris D, Zhang Y, Gaikwad A, Kantarjian HM and Verstovsek S: Preclinical characterization of atiprimod, a novel JAK2 AND JAK3 inhibitor. Invest New Drugs 29: 818-826, 2011.

17. Knapper S, Burnett AK, Littlewood T, Kell WJ, Agrawal S, Chopra R, Clark R, Levis MJ and Small D: A phase 2 trial of the FLT3 inhibitor lestaurtinib (CEP701) as first-line treatment for older patients with acute myeloid leukemia not considered fit for intensive chemotherapy. Blood 108: 3262-3270, 2006.

18. Hexner EO, Serdikoff C, Jan M, Swider CR, Robinson C, Yang S, Angeles T, Emerson SG, Carroll M, Ruggeri B, et al: Lestaurtinib (CEP701) is a JAK2 inhibitor that suppresses JAK2/STAT5 signaling and the proliferation of primary erythroid cells from patients with myeloproliferative disorders. Blood 111: 5663-5671, 2008. 
19. Children's Oncology Group: Combination chemotherapy with or without lestaurtinib in treating younger patients with newly diagnosed acute lymphoblastic leukemia. https://clinicaltrials. gov/ct2/show/NCT00557193. Verified September 2015.

20. Tapley P, Lamballe F and Barbacid M: K252a is a selective inhibitor of the tyrosine protein kinase activity of the trk family of oncogenes and neurotrophin receptors. Oncogene 7: 371-381, 1992.

21. Moon C, Yoo J-Y, Matarazzo V, Sung YK, Kim EJ and Ronnett GV: Leukemia inhibitory factor inhibits neuronal terminal differentiation through STAT3 activation. Proc Natl Acad Sci USA 99: 9015-9020, 2002.

22. Bharathkumar H, Mohan CD, Rangappa S, Kang T, Keerthy HK, Fuchs JE, Kwon NH, Bender A, Kim S, Basappa, et al: Screening of quinoline, 1,3-benzoxazine, and 1,3-oxazine-based small molecules against isolated methionyl-tRNA synthetase and A549 and HCT116 cancer cells including an in silico binding mode analysis. Org Biomol Chem 13: 9381-9387, 2015.

23. Basappa, Sugahara K, Thimmaiah KN, Bid HK, Houghton PJ and Rangappa KS: Anti-tumor activity of a novel HS-mimeticvascular endothelial growth factor binding small molecule. PLoS One 7: e39444, 2012.

24. Rakesh KS, Jagadish S, Vinayaka AC, Hemshekhar M, Paul M, Thushara RM, Sundaram MS, Swaroop TR, Mohan CD, Basappa et al: A new ibuprofen derivative inhibits platelet aggregation and ROS mediated platelet apoptosis. PLoS One 9: e107182, 2014.

25. Anusha S, Anandakumar BS, Mohan CD, et al: Preparation and use of combustion-derived $\mathrm{Bi} 2 \mathrm{O} 3$ for the synthesis of heterocycles with anti-cancer properties by Suzuki-coupling reactions. RSC Advances 4: 52181-52188, 2014.

26. Bharathkumar H, Mohan CD, Ananda H, Fuchs JE, Li F, Rangappa S, Surender M, Bulusu KC, Girish KS, Sethi G, et al: Microwave-assisted synthesis, characterization and cytotoxic studies of novel estrogen receptor $\alpha$ ligands towards human breast cancer cells. Bioorg Med Chem Lett 25: 1804-1807, 2015.

27. Anilkumar NC, Sundaram MS, Mohan CD, Rangappa S, Bulusu KC, Fuchs JE, Girish KS, Bender A, Basappa and Rangappa KS: A one pot synthesis of novel bioactive trisubstitute-condensed-imidazopyridines that targets snake venom phospholipase A2. PLoS One 10: e0131896, 2015.

28. Keerthy HK, Mohan CD, Sivaraman Siveen K, Fuchs JE, Rangappa S, Sundaram MS, Li F, Girish KS, Sethi G, Basappa, et al: Novel synthetic biscoumarins target tumor necrosis factor-a in hepatocellular carcinoma in vitro and in vivo. J Biol Chem 289: 31879-31890, 2014.

29. Anusha S, Mohan CD, Ananda H, Baburajeev CP, Rangappa S, Mathai J, Fuchs JE, Li F, Shanmugam MK, Bender A, et al: Adamantyl-tethered-biphenylic compounds induce apoptosis in cancer cells by targeting $\mathrm{Bcl}$ homologs. Bioorg Med Chem Lett 26: 1056-1060, 2016.

30. Anusha S, Cp B, Mohan CD, Mathai J, Rangappa S, Mohan S, Chandra, Paricharak S, Mervin L, Fuchs JE, et al: A Nano-MgO and ionic liquid-catalyzed 'green' synthesis protocol for the development of adamantyl-imidazolo-thiadiazoles as antituberculosis agents targeting sterol $14 \alpha$-demethylase (CYP51) PLoS One 10: e 0139798, 2015.

31. Baburajeev CP, Dhananjaya Mohan C, Ananda H, Rangappa S, Fuchs JE, Jagadish S, Sivaraman Siveen K, Chinnathambi A, Ali Alharbi S, Zayed ME, et al: Development of novel triazolothiadiazoles from heterogeneous 'Green' catalysis as protein tyrosine phosphatase 1B inhibitors. Sci Rep 5: 14195, 2015.

32. Ashwini N, Garg M, Mohan CD, Fuchs JE, Rangappa S, Anusha S, Swaroop TR, Rakesh KS, Kanojia D, Madan V, et al: Synthesis of 1,2-benzisoxazole tethered 1,2,3-triazoles that exhibit anticancer activity in acute myeloid leukemia cell lines by inhibiting histone deacetylases, and inducing p21 and tubulin acetylation. Bioorg Med Chem 23: 6157-6165, 2015.

33. Pandey V, Perry JK, Mohankumar KM, Kong XJ, Liu SM, Wu ZS, Mitchell MD, Zhu T and Lobie PE: Autocrine human growth hormone stimulates oncogenicity of endometrial carcinoma cells. Endocrinology 149: 3909-3919, 2008.
34. Neelgundmath M, Dinesh KR, Mohan CD, Li F, Dai X, Siveen KS, Paricharak S, Mason DJ, Fuchs JE, Sethi G, et al: Novel synthetic coumarins that targets NF- $\mathrm{KB}$ in hepatocellular carcinoma. Bioorg Med Chem Lett 25: 893-897, 2015.

35. Bharathkumar H, Paricharak S, Dinesh KR, et al: Synthesis, biological evaluation and in silico and in vitro mode-of-action analysis of novel dihydropyrimidones targeting PPAR- $\gamma$. RSC Advances 4: 45143-45146, 2014.

36. Morin PJ: Drug resistance and the microenvironment: Nature and nurture. Drug Resist Updat 6: 169-172, 2003.

37. Aggarwal BB, Vijayalekshmi RV and Sung B: Targeting inflammatory pathways for prevention and therapy of cancer: Short-term friend, long-term foe. Clin Cancer Res 15: 425-430, 2009.

38. Rajendran P, Li F, Manu KA, Shanmugam MK, Loo SY, Kumar AP and Sethi G: $\gamma$-Tocotrienol is a novel inhibitor of constitutive and inducible STAT3 signalling pathway in human hepatocellular carcinoma: Potential role as an antiproliferative, pro-apoptotic and chemosensitizing agent. Br J Pharmacol 163: 283-298, 2011.

39. Firestone GL and Sundar SN: Anticancer activities of artemisinin and its bioactive derivatives. Expert Rev Mol Med 11: e32, 2009.

40. Castellano M, Pollock PM, Walters MK, Sparrow LE, Down LM, Gabrielli BG, Parsons PG and Hayward NK: CDKN2A/p16 is inactivated in most melanoma cell lines. Cancer Res 57:4868-4875, 1997.

41. Keerthy HK, Garg M, Mohan CD, Madan V, Kanojia D, Shobith R, Nanjundaswamy S, Mason DJ, Bender A, Basappa, et al: Synthesis and characterization of novel 2-amino-chromenenitriles that target $\mathrm{Bcl}-2$ in acute myeloid leukemia cell lines. PLoS One 9: e107118, 2014.

42. Gross A, McDonnell JM and Korsmeyer SJ: BCL-2 family members and the mitochondria in apoptosis. Genes Dev 13: 1899-1911, 1999.

43. Singhai R, Patil VW, Jaiswal SR, Patil SD, Tayade MB and Patil AV: E-Cadherin as a diagnostic biomarker in breast cancer. N Am J Med Sci 3: 227-233, 2011.

44. Martin TA, Mansel RE and Jiang WG: Loss of occludin leads to the progression of human breast cancer. Int J Mol Med 26: 723-734, 2010.

45. Zhuo H, Jiang K, Dong L, Zhu Y, Lü L, Lü Y, Zhang YB, Zhang H, Ye YJ and Wang S: Overexpression of $\mathrm{N}$-cadherin is correlated with metastasis and worse survival in colorectal cancer patients. Chin Sci Bull 58: 3529-3534, 2013.

46. Satelli A and Li S: Vimentin in cancer and its potential as a molecular target for cancer therapy. Cell Mol Life Sci 68: 3033-3046, 2011.

47. Lieblein JC, Ball S, Hutzen B, Sasser AK, Lin HJ, Huang TH, Hall BM and Lin J: STAT3 can be activated through paracrine signaling in breast epithelial cells. BMC Cancer 8: 302, 2008

48. Yuan ZL, Guan YJ, Wang L, Wei W, Kane AB and Chin YE: Central role of the threonine residue within the $\mathrm{p}+1$ loop of receptor tyrosine kinase in STAT3 constitutive phosphorylation in metastatic cancer cells. Mol Cell Biol 24: 9390-9400, 2004.

49. Zhang W, Qian P, Zhang X, Zhang M, Wang H, Wu M, Kong X, Tan S, Ding K, Perry JK, et al: Autocrine/paracrine human growth hormone-stimulated microRNA 96-182-183 cluster promotes epithelial-mesenchymal transition and invasion in breast cancer. J Biol Chem 290: 13812-13829, 2015.

50. Wu Y, Diab I, Zhang X, Izmailova ES and Zehner ZE: Stat3 enhances vimentin gene expression by binding to the antisilencer element and interacting with the repressor protein, ZBP-89. Oncogene 23: 168-178, 2004

51. Elkholi R, Floros KV and Chipuk JE: The role of BH3-only proteins in tumor cell development, signaling, and treatment. Genes Cancer 2: 523-537, 2011.

52. Crown J, O'Shaughnessy J and Gullo G: Emerging targeted therapies in triple-negative breast cancer. Ann Oncol (Suppl 6): vi56-65, 2012. 